\title{
Editorial
}

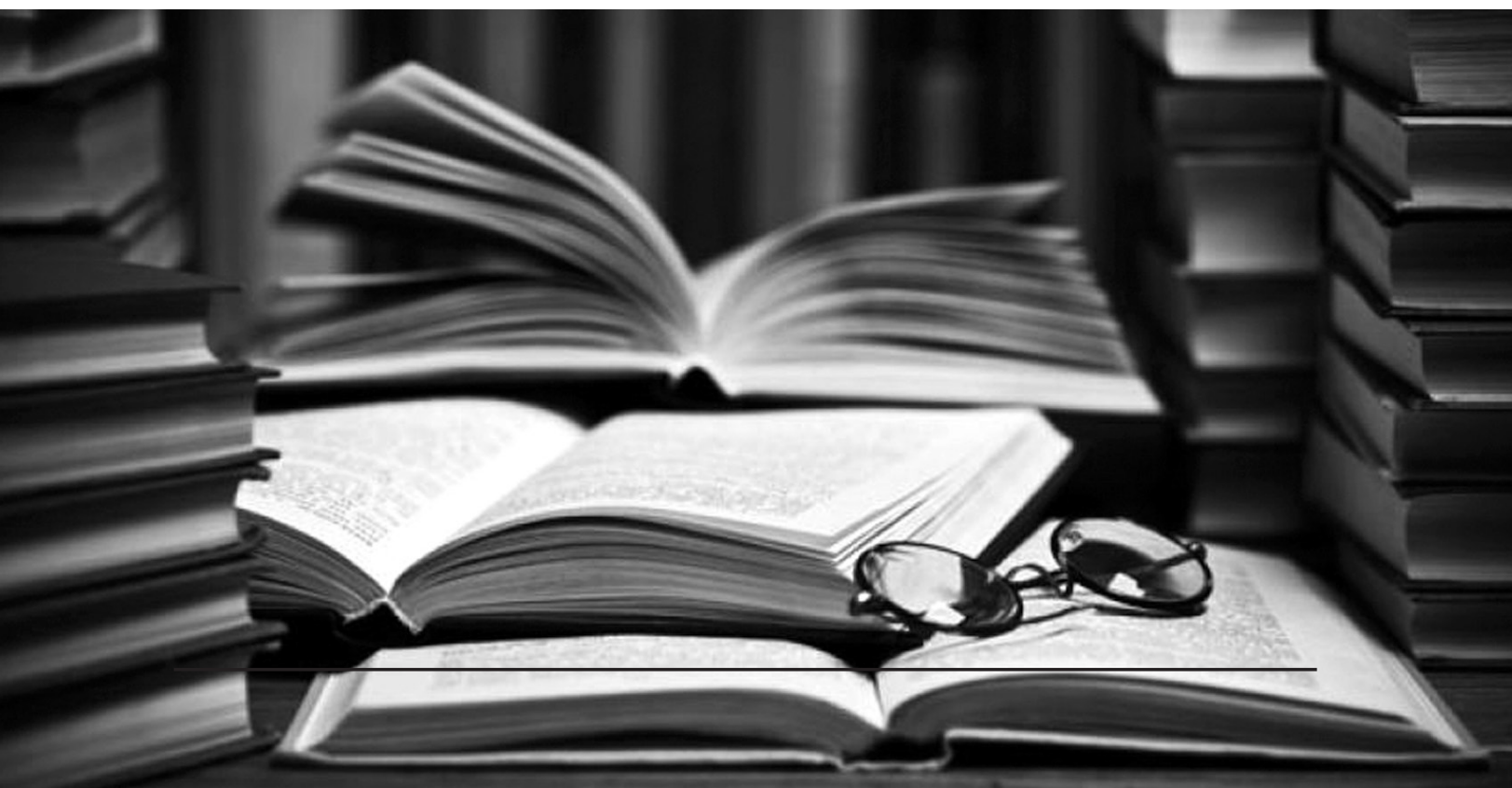





\section{Hacia la producción científica sin fronteras}

La producción científica es un valor universal, el modelo de desarrollo que vivimos hace posible que mediante la publicación de calidad se tenga acceso a lo más actual, relevante e inédito de la ciencia.

Pero la producción de la ciencia no es igual en todas las materias ni mucho menos en todos los idiomas, ni en todos los países. Es por ello que resulta importante saber y conocer el lugar desde donde partimos.

Según el Scientifica Journals Ranking (SJR) de los aproximadamente 16 millones de artículos citables en Scopus, solamente el 7.7 son de ciencias sociales y humanidades. La Unesco en su informe mundial de ciencias sociales de 2016 advirtió que alrededor del mundo, son cinco países o regiones las que concentran el $72 \%$ de las publicaciones a nivel mundial: Unión Europea, China, Estados Unidos, Japón y Rusia.

Indudablemente es un enorme reto para nosotros saber, que de la producción científica el $75 \%$ de revistas de Ciencias Sociales en el Mundo se editan en Europa y América del Norte y el $85.3 \%$ se editan en ingles

Por lo tanto, el 97 por ciento de la producción científica mundial se produce en ingles y tan solo el $0.24 \%$ se produce en español; pese a que existen 450 millones de hispano hablantes en el mundo frente a los 360 millones de personas que hablan ingles como lengua materna.

Otro dato que confirma lo anterior es que del total de Revistas con ISSN (Número Internacional Normalizado de Publicaciones Periódicas) tan solo el 4.4 $\%$ son en lengua española.

¿Como es que sucede esto? gran parte de la repuesta tiene que ver con que el $90 \%$ de las instituciones de enseñanza superior en América Latina solo se 
dedican a las actividades docentes y no aportan a la investigación científica, por lo tanto, no participan en los procesos de difusión de la ciencia, lo cual es muy preocupante si consideramos que la ciencia tiene como fin resolver problemas, y es mediante la innovación como podemos encontrar las mejores respuestas para transformar nuestra realidad.

Sin embargo, el tema no se reduce a números y cifras, por el contrario tiene que ver con la posibilidad de lograr un impacto en el desarrollo de nuestros países, ya que la información al transformarse en conocimiento genera innovación que conlleva al crecimiento económico, todo lo cual contribuye al desarrollo, lo que significa que sin creación de nuevo conocimiento no hay desarrollo.

Por ello, los países invierten en la producción científica como política pública que fomenta el desarrollo social, ejemplo de ello es lo que hace el Estado Mexicano a través del Consejo Nacional de Ciencia y Tecnología que establece parámetros de calidad y buenas prácticas en las publicaciones nacionales para que logren trascender en el ámbito internacional.

Actualmente tan sólo 200 revistas forman parte del Sistema, las cuales han pasado una rigurosa evaluación y han sido admitidas al índice de revistas de calidad bajo alguno de los 4 niveles existentes: Revistas en Desarrollo (RED); Revistas en Consolidación (REC); Revistas de Competencia Nacional (RCN) y Revistas de Competencia Internacional (RCI).

Nuestra Revista Derecho Global. Estudios sobre Derecho y Justicia, ha sido recientemente evaluada y clasificada como Revista de Competencia Internacional, lo cual es sin duda alguna un gran compromiso que nos llena de enorme satisfacción.

Nos congratulamos por ello y agradecemos a todos nuestros autores, lectores y equipo de trabajo editorial.

En definitiva, creemos que el camino hacia una mayor visibilidad de la producción científica de las ciencias sociales en idioma español es una tarea que corresponde a Latino América, y nosotros, desde la Universidad de Guadalajara contribuimos a que ello sea una realidad.

Es importante entender que incentivar el desarrollo de la investigación y apoyar los sistemas de difusión de las revistas científicas en la región es un objetivo prioritario dentro de las políticas públicas de los países hispano parlantes. 
Lo cual, sólo puede conseguirse con una educación de calidad que haga posible tanto la docencia como la investigación, para que se logre transformar la información en una economía del conocimiento que haga posible disminuir la pobreza y contribuya al desarrollo sustentable, favoreciendo de ésta manera el logro de los objetivos 2030 de la Organización de las Naciones Unidas.

\author{
Guadalajara, Jalisco, invierno 2020 \\ Dra. Silvia Patricia López González \\ Directora-Editora
}

